\title{
Characterization of Carbohydrate Surface Markers on Mouse Embryonic Stem Cells
}

\author{
Zhenwei He ${ }^{2,1, \#}$, Yue An ${ }^{1,3, \#}$, Gang Shi, ${ }^{4,1,}$, Yingwei Lin ${ }^{1,3}$, Jiliang Hu${ }^{5 *}$ and Yali Li ${ }^{1 *}$ \\ ${ }^{1}$ Department of Biochemistry and Molecular Biology, Dalian Medical University, Dalian 116044, China \\ ${ }^{2}$ Department of Neurology, Forth Affiliated Hospital of China Medical University, Shenyang, Liaoning Province China, \\ ${ }^{3}$ Department of Clinical Laboratory, The Second Affiliated Hospital of Dalian Medical University, Dalian, Liaoning 116027, China \\ ${ }^{4}$ Department of Colorectal Surgery, Liaoning Cancer Hospital and Institute, Cancer Hospital of China Medical University, Shenyang 110042, China \\ ${ }^{5}$ Department of Neurosurgery, The Shenzhen People's Hospital (The Second Clinical Medical Collage of Jinan University), Guangdong 518020, China \\ "These authors have contributed equally to this work
}

\begin{abstract}
Glycosylation of proteins and lipids on cell surface have been shown to be important in maintaining pluripotency and stem cell fate in embryonic stem cells. Lectins have been widely used to characterize carbohydrate modifications on cell surface of embryonic stem cells to determine pluripotency and stem cell fate. In the present study, a panel of 14 lectins and carbohydrate antibodies was used to characterize the carbohydrate surface markers of mouse Embryonic Stem (ES) Cells. SSEA-1-positive mouse ES cells were firstly enriched and the carbohydrate profile of the cells was determined by flow cytometry and immunocytochemistry. Enrichment of mouse ES cells yielded approximately 99.95 $\pm 0.87 \%$ of SSEA-1-positive mouse ES cells. A uniform and high percentage of binding was observed for PNA, DSL, JAC, GNL, PSA and LTL, with PNA, DSL, JAC and GNL having similar percentage of binding to SSEA-1 (99.9\%), while PSA and LTL binding were approximately 95\%-99\%. Partial binding of WFL, SNA and AAL were observed in mouse ES cells which was also reflected by the respective immunocytochemistry images. A very low percentage of binding was observed for MAA and UEAI. The data showed that high expression of mannose, $\mathrm{N}$-acetyllactosamine and galactose are present on the cell surface of mouse ES cells. Some reliable surface markers that can be used to determine pluripotency are PNA, DSL, JAC and GNL, which showed similar binding to SSEA-1, a well-established pluripotent marker. Taken together, the data has provided information on the cell surface carbohydrate profile of mouse ES cells.
\end{abstract}

Keywords: Mouse embryonic stem cells; SSEA-1; Lectins

Abbrevations: Mouse ESCs: Mouse Embryonic Stem Cells; SSEA-1: Stage Specific Embryonic Antigen-1; GalNAc: N-acetylgalactosamine; LIF: Leukemia Inhibitory Factor; MEF: Mouse Embryonic Fibroblast; PBS: Phosphate Buffered Saline; BSA: Bovine Serum Albumin; UEAI: Ulex europaeus Agglutinin I; LTL: Lotus tetragonolobus Lectin; PSA: Pisum sativum Agglutinin; GNL: Galanthus nivalis Lectin; AAL: Aleuria aurantia Lectin; PNA: Peanut Agglutinin; JAC: Jacalin; MAA, MALII: Maackia amurensis Lectin II; SNA: Sambucus nigra Agglutinin; SBNL: Elderberry Bark Lectin ; DSL: Datura stramonium Lectin; WFL: Wisteria floribunda Lectin; FITC: Fluorescein Isothiocyanate

\section{Introduction}

Mouse Embryonic Stem (ES) Cells were first derived from inner cell mass of mouse blastocysts isolated from pre-implantation embryos on feeder layers [1,2]. The use of mouse ES cells provided a deeper understanding of the mechanisms of cell differentiation and observations of the physiological consequences of genetic mutations. Most importantly, the pluripotent nature of mouse ES cells enabled the generation of transgenic and knockout mice, which has revolutionized genetic research, allowing the development of countless animal models for human diseases [3].

Key regulators of pluripotency and self-renewal including Oct4 and Nanog are well known markers of mouse ES cells [4]. These transcription factors regulate the expression of numerous genes responsible for stem cell fate and pluripotency such as Sox2, Foxd3, Setb1, Rif1 and Esrrb [4]. Apart from transcription factors, cell surface markers of mouse ES cells for pluripotency have also been identified. The most common cell surface carbohydrate antigen specifically found on murine ES cells is the stage specific embryonic antigen 1 (SSEA1) - also known as Lewis $\mathrm{x}$ or CD15 - which is important for cell-cell adhesion in tightly compacted colonies of mouse ES cells [5-7]. Other surface markers include CD324, CD90, CD117, CD9 and CD326 [8].

Carbohydrate modifications of proteins and lipids on cell surface of ES cells have also been reported to be important in maintenance of pluripotency and stem cell fate [9]. Glycosylation, a process by which glycans or carbohydrate are attached to proteins or lipids, are common post-translational carbohydrate modifications. Glycans play essential roles in biological process such as cell development and differentiation. Lectins are proteins that bind to glycans and are universally present in animals, plants and bacteria. Lectin profiles are widely used to characterize carbohydrates of glycoproteins, glycolipids or polysaccharides. Venable was the first to characterize carbohydrate patterns through lectin profiles in SSEA-4-enriched human ES cells [10]. Additionally, a panel of lectin biomarkers has been identified for the isolation of pluripotent human ES cells [9]. Lectin probes and more recently, lectin microarrays have also been utilized to distinguish undifferentiated from differentiated ES cells in both human and mouse ES cells [11-13].

*Corresponding authors: Yali Li, Department of Biochemistry and Molecular Biology, Dalian Medical University, Dalian 116044, China, Tel: +86 755 22948200; E-mail: yalilipaper@Gmail.com

Jiliang Hu, Department of Neurosurgery, The Shenzhen People's Hospital (The Second Clinical Medical Collage of Jinan University), Guangdong 518020 , China, Tel: +86 208522 0010; E-mail: hforestwolf@163.com

Received July 24, 2016; Accepted August 12, 2016; Published August 19, 2016

Citation: He Z, An Y, Shi G, Lin Y, Hu J, et al. (2016) Characterization of Carbohydrate Surface Markers on Mouse Embryonic Stem Cells. J Stem Cell Res Ther 6: 353. doi: 10.4172/2157-7633.1000353

Copyright: (c) $2016 \mathrm{He} \mathrm{Z}$, et al. This is an open-access article distributed under the terms of the Creative Commons Attribution License, which permits unrestricted use, distribution, and reproduction in any medium, provided the original author and source are credited. 
In the present study, carbohydrate profiles of ES-D3 and ESC57BL/6 mouse ES cell lines were analyzed. These cell lines have been shown to express SSEA-1, the pluripotency marker in mouse ES cells $[14,15]$. SSEA-1-positive cells were enriched by flow cytometry before carbohydrate analysis using a panel of 14 carbohydrate antibodies and lectins. The study showed distinct expression and localization of carbohydrate and lectins on cell surface of the mouse ES cells.

\section{Materials and Methods}

\section{Chemicals}

All cell culture reagents were purchased from Invitrogen Life Technologies (Merelbeke, Belgium), unless indicated otherwise. AntiSSEA-1 antibody was purchased from Santa Cruz Biotechnology Inc. Rat anti-mouse IgM-microbeads and LS+ positive selection column were purchased from Miltenyi Biotec Inc. (Miltenyi Biotec. Inc., Bergisch Gladbach, Germany). L3, L4 and L5 antibodies were produced as previously described and presented by Melitta in Hamberg University [16-19]. R-Phycoerythin (R-PE)-conjugated mouse anti-rat monoclonal, R-Phycoerythin (R-PE)-conjugated rat anti-mouse IgM monoclonal $\mathrm{Ab}$, PerCP-CY5.5-conjugated rat antimouse IgM monoclonal, PerCP-CY5.5-conjugated mouse anti-rat IgM monoclonal Ab, PerCP-CY5.5-conjugated streptavidin and R-PEconjugated rat anti-mouse IgM monoclonal antibodies were purchased from BD Biosciences (Franklin Lakes, NJ, USA). Biotinylated lectins and Texas Red Avidin D were purchased from Vector Laboratories, Inc. (Burlingame, CA, USA). FITC-conjugated rat anti-mouse IgM $\mathrm{Ab}$ and $\mathrm{Cy3}$-conjugated mouse anti-rat IgM Ab were purchased from Invitrogen Detection Technologies, Oregon, USA. Leukemia inhibitory factor (LIF) was purchased from Chemicon Incorporation, Temecula, CA, USA.

\section{Cell culture}

All cell culture reagents were purchased from Invitrogen Life Technologies (Merelbeke, Belgium) unless indicated otherwise. ESD3 embryonic stem cell line derived from the blastocysts of 129 S2/ SvPas mouse and ES-C57BL/6 embryonic stem cell line derived from the C57BL/6J mouse were purchased from ATCC (Global Bioresource CenterTM, Manassas, USA). ES cells were grown in ES-DMEM supplemented with $15 \%$ ES-FBS, $1 \times$ non-essential amino acids, $2 \mathrm{mM}$ L-glutamine, $50 \mathrm{U} / \mathrm{mL}$ penicillin, $50 \mu \mathrm{g} / \mathrm{mL}$ streptomycin, and $0.1 \mathrm{mM}$ 2-mercaptoethanol. Undifferentiated ES cells were grown on mitomycin C-treated mouse embryonic fibroblasts (MEFs) in the presence of $1,000 \mathrm{U} / \mathrm{mL}$ leukemia inhibitory factor (LIF; Chemicon Inc.). ES cells were passaged every 2 or 3 days using $0.05 \%$ trypsin/0.04\% EDTA for 2-3 minutes or mechanical dissection with BD Medimachine. Flow cytometry assay was performed using routinely maintained adherent mouse ES cell colonies.

\section{Enrichment of SSEA-1 positive mouse embryonic stem cells (ESCs)}

Murine ES cells were grown in $10 \mathrm{~cm}$ dishes and trypsin/EDTA passaged into single cell suspensions as described above. Cells were incubated at $4^{\circ} \mathrm{C}$ for 30 minutes in 1:10 dilution of purified anti-mouse IgM in D/G buffer. D/G buffer consisted of $0.5 \%$ BSA and $2 \mathrm{mM}$ EDTA in phosphate buffered saline (PBS), pH7.4. After incubation, $2 \mathrm{ml}$ $\mathrm{D} / \mathrm{G}$ buffer was added and cells were re-suspended and centrifuged at $300 \mathrm{~g}$ for 5 minutes. Supernatant was removed, leaving the cell pellet intact, and cells were washed again in $\mathrm{D} / \mathrm{G}$ buffer and re-suspended. After centrifugation, cells were incubated at $4^{\circ} \mathrm{C}$ for 30 minutes in $1: 10$ dilution of SSEA-1 antibody in D/G buffer. After washing with $D / G$ buffer for 3 times, a 1:4 dilution of secondary anti-mouse IgM-beads in $\mathrm{D} / \mathrm{G}$ buffer were added to the cell pellet, and the re-suspended pellet was incubated at $4^{\circ} \mathrm{C}$ for 5 minutes. After incubation, $5 \mathrm{ml}$ of $\mathrm{D} / \mathrm{G}$ buffer was added to wash the cell pellet, followed by centrifugation (300 g) for 5 minutes. This process was repeated two more times with $5 \mathrm{ml}$ $\mathrm{D} / \mathrm{G}$ buffer. The cells were finally re-suspended in $500 \mu \mathrm{l}$ of $\mathrm{D} / \mathrm{G}$ buffer before being applied to a pre-washed magnetic beads column. The flow through from the column was collected and applied to the magnetic beads column thrice. Then, $5 \mathrm{ml}$ of $\mathrm{D} / \mathrm{G}$ buffer was applied to the magnetic beads column to obtain the eluate. The eluate was collected and cells were counted. Cells were then subjected to flow cytometry. Flow cytometry results presented here are from mouse ES cells that were used immediately after the enrichment.

\section{Flow cytometry assay}

Cell surface carbohydrate expression of SSEA-1 enriched mouse ES cells was assessed by indirect immunofluorescence detected by flow cytometry to provide a quantitative binding percentage and fluorescence intensity of SSEA-1 Ab, carbohydrate antibodies and lectins. FACSCalibur (Becton-Dickinson, San Jose, USA) equipped with an argon laser with emission wavelength at $488 \mathrm{~nm}$ was used. Flow cytometry results presented here are from mESCs that were used immediately after the SSEA-1 positive cell enrichment procedure. CellQuest Pro software (Becton-Dickinson) was used for cell acquisition and analysis. Mouse ES cells were prepared, cultured and harvested into single cell suspensions using trypsinization as described above. The cells were digested with $0.05 \%$ trypsin and washed twice with PBS (Gibco, Long Island, USA). Single cell suspension was prepared in PBS with 10\% FBS with the concentration adjusted to 107 cells/ml for indirect antibody labeling. The SSEA-1 positive ES cells were enriched as described above. Then, cells were placed in $4 \mathrm{ml}$ sterile conical tubes (Falcon, Becton-Dickison) in aliquots of 500,000 cells each and stained with one of the 14 carbohydrate antibodies and lectins. Cells were washed 3 times with PBS and subsequently stained with secondary antibodies. Cells were double stained with one of the 14 carbohydrate antibodies and lectins and SSEA-1 Ab, then stained with secondary antibodies after washing with PBS. The secondary antibodies were chosen so that there would not be any overlap in the emission/ excitation wavelengths and so that double staining could be performed. Unstained, enriched mouse ES cells and enriched mouse ES cells stained with secondary antibodies alone were used as controls. Flow cytometry was performed using a Beckman Coulter Cytomics FC 500 Flow Cytometer. Data analysis was performed using the RXP Analysis Software by Beckman Coulter and Windows Multi Document Interface for Flow Cytometry (WinMDI 2.8). At least three independent assays were carried out using both ES-D3 cell line and ES-C57BL/6 mouse ES cell line.

\section{Immunocytochemical staining}

Immunocytochemistry staining was used to analyze the localization and staining patterns of cell surface carbohydrate expression and SSEA1 on routinely maintained adherent cultures of mouse ES cells. Mouse ES cells were fixed in $4 \%$ paraformaldehyde in PBS for 30 minutes and then washed 3 times with PBS. After blocking in 1\% BSA for 1 hour, cells were double stained with one of the 11 biotinylated lectins, 3 carbohydrate antibodies and SSEA-1 Ab for 1 hour, followed by washing with PBS thrice. Cells were stained with secondary antibodies for 1 hour and then washed 3 times with PBS. After drying, cells were mounted with Hard SetTM fluorescence mounting medium (Vector Laboratories, Inc. Burligame, CA, USA) including DAPI to detect cell nuclei. Controls of unstained cells were obtained by incubation with 
secondary antibodies alone. All slides were visualized using a LSM510 laser microscope. Individual color channels were captured separately and merged using the LSM510 software.

\section{Statistical analysis}

All data were expressed as mean \pm S.E.M. Statistical evaluations were achieved by one-way analysis of variance and Student's t-test. Differences were considered to be significant when $\mathrm{p}<0.05$.

\section{Results}

\section{Carbohydrate analysis using flow cytometry}

To decrease non-specific binding, purified anti-mouse IgM was used to block mouse ES cells. After blocking, the non-specific binding was decreased from $14.36 \%$ to $3.61 \%$ (Figure S1). To obtain undifferentiated mouse ES cells, magnetic beads sorting method was used to enrich SSEA-1 positive mouse ES cells. After enrichment, about $99.95 \pm 0.87 \%$ of mouse ES cells were SSEA-1 positive (Figure 1). To determine the presence and binding percentage of 14 chosen carbohydrate Abs and lectins on pluripotent mouse ES cell surfaces, both karyotypically normal mouse ES cell lines (ES-D3 and ESC57BL/6) were analyzed using flow cytometry with the panel of Abs and lectins together with the pluripotency marker, SSEA-1. A broad range of binding percentages was observed (Figure 2). The highest binding percentages were detected using PNA, DSL, JAC, GNL, PSA, $\mathrm{AAL}$ and LTL. The binding percentages for PNA, DSL, JAC and GNL were similar to that of SSEA-1, which showed over $99.9 \%$ of positive binding in enriched mouse ES cells. Figures 3A-3D show the shifted histogram plots of GNL and DSL, as representatives of these high percentage binding Abs and lectins. The flurorescence intensity of
A

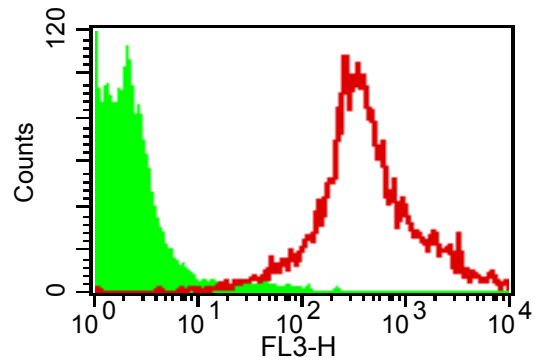

B

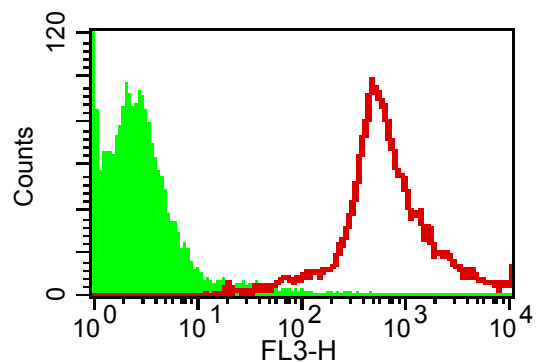

Figure 1: Effect of magnetic beads sorting, The histogram of unstained, control mouse ESCs (green) and cells stained with SSEA-1 antibody (red) after enrichment. A: the sorting results of mouse ES-D3 cells, B: the sorting results of mouse ES-C57BL/6 cells.

A

120

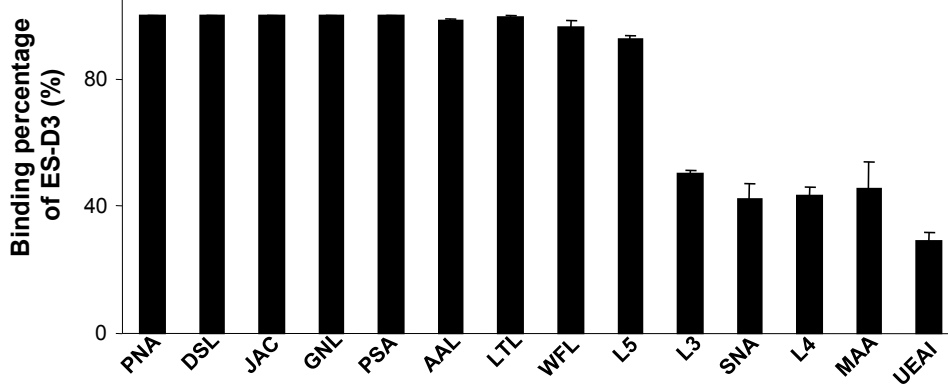

B

120

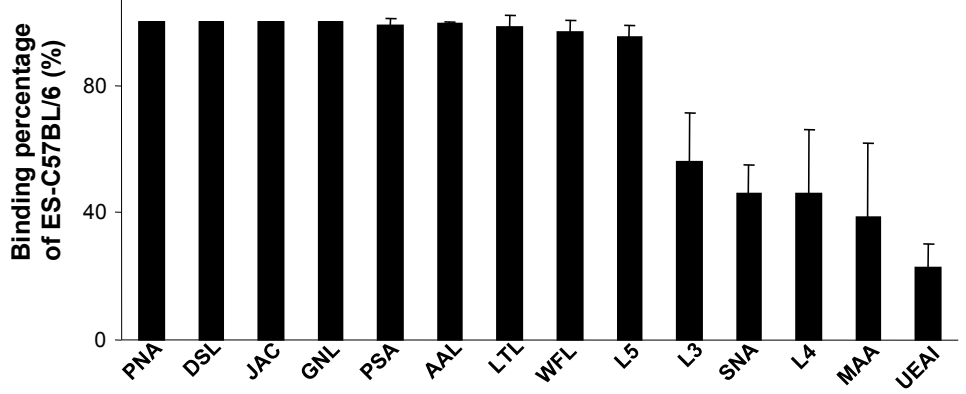

Figure 2: Quantitation of lectins and carbohydrate Abs binding on pluripotent mouse ES cells surface, To determine the presence and binding percentage of 14 chosen carbohydrate Abs and lectins, karyotypically normal mouse ES cell lines (A: ES-D3 and B: ES-C57BL/6) were analyzed using flow cytometry with the panel of Abs and lectins and the pluripotency marker, SSEA-1. The data are presented as mean \pm SD of 3 independent assays. 
DSL binding was higher than GNL binding (Figure S2). The binding percentages of PSA, AAL and LTL ranged from 95-99\% of enriched mouse ES cells. Two lectins, MAA and UEAI, binding percentage were very low. Analysis of MAA and UEAI histograms showed a little peak shifts using these lectins (Figures $3 \mathrm{E}$ and $3 \mathrm{~F}$ ).

Some lectins were found to partially bind to mouse ES cell colonies. These lectins revealed two distinct subpopulations of cells that include a SSEA-1(+)/lectin(-) population and a SSEA-1(+)/lectin $(+)$ population. For example, Figure $3 \mathrm{G}$ shows a representative histogram plot of WFL which shows a large population of WFL positive (weak) and negative cells that overlap the unstained control cells; However, the arrow indicates another smaller population of cells that shows a peak shift representing strong WFL binding. Figures $3 \mathrm{H}-3 \mathrm{~L}$ shows the comparison of unstained control cells to the shifted plot of SNA in which there are two distinct populations of cells present: a SSEA$1(+) / \mathrm{SNA}(-)$ population containing the majority of cells, and a smaller but still distinct SSEA-1(+)/SNA(+) population indicated by the arrow. Lectins that bound in this way include WFL, SNA and AAL.

\section{Carbohydrate analysis using immunocytochemical method}

Both ES-D3 and ES-C57BL/6 mouse ES cell lines were analyzed by immunocytochemistry to determine the localization of carbohydrates and whether particular staining patterns were present in adherent colonies maintained in culture. Cells were either passaged mechanically or by trypsinization and we did not observe obvious differences in mouse ES cell colony staining patterns between these passage methods.

Immunocytochemistry results of all 14 carbohydrate Abs and lectins supported our flow cytometry analysis. Six lectins (PNA, DSL, JAC, GNL, PSA and AAL) bound throughout the colonies without any localized patterns of binding. They appeared to bind to cells that also expressed SSEA-1. Figures 4A-C shows a mouse ES cell colony stained with DSL (red) and SSEA-1 (green). We also observed interesting patterns of carbohydrate expression for the Abs and lectins that showed two subpopulations of cells when analyzed using immunocytochemistry. WFL bound to distinct regions of a SSEA-1 positive colony (Figures $4 \mathrm{D}$ and $4 \mathrm{E}$ ), in contrast to the more uniform binding described above. In Figure 4D, the arrow shows a region where there is no WFL binding, but this region is SSEA-1 positive, as shown in Figure 4E. In Figure 4F, in the peripheral part of the same mouse ES cell colony, the binding of SSEA-1 Ab and L5 Ab are strong, conversely, in the middle of the colony, cells are beginning to lose SSEA-1Ab binding (green) but still have strong L5 Ab binding (red). Using immunocytochemistry, we also demonstrated that a small percentage of UEAI and MAA were bound to mouse ES cell colonies. Figures 4G4I show a mouse ES cell colony which is SSEA-1 positive (green) and is stained with DAPI (blue) but show almost no UEAI binding.

\section{Discussion}

Undifferentiated mouse ES cells are commonly characterized by the presence of CD9, SSEA-1 and Forssman antigen on the cell surface $[12,20,21]$. Apart from these well-established markers, undifferentiated ES cells have also been characterized by the unique carbohydrate antigen profiles present on the cell surface $[10,13]$. In the present study, SSEA-1-positive undifferentiated mouse ES cells were enriched and
A

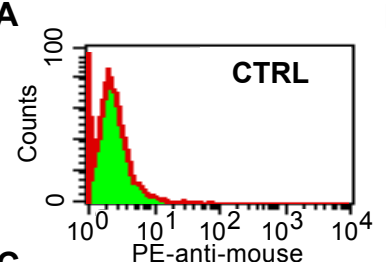

C

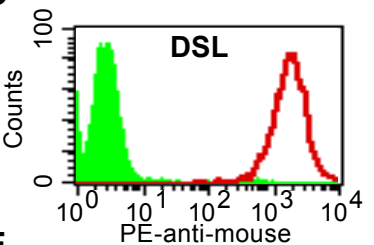

E

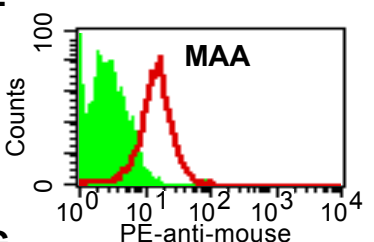

G

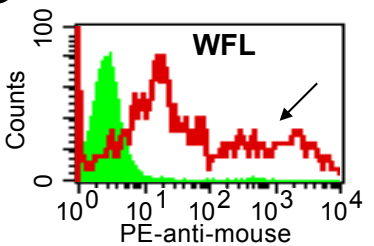

B
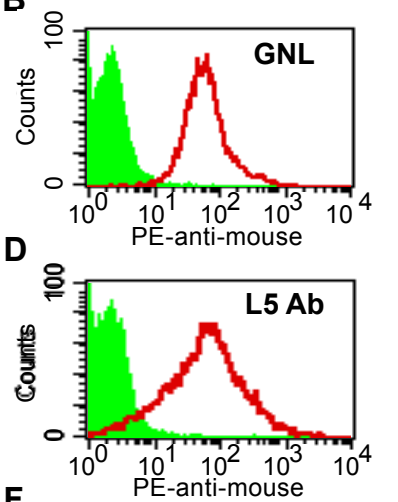

$F$
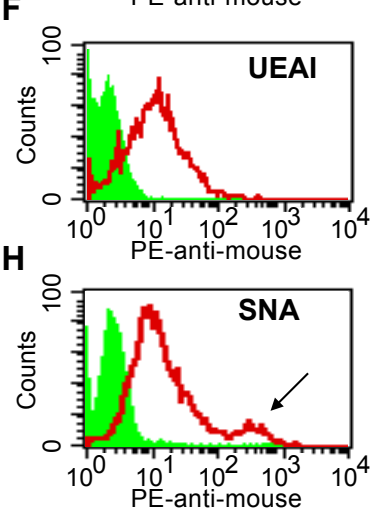
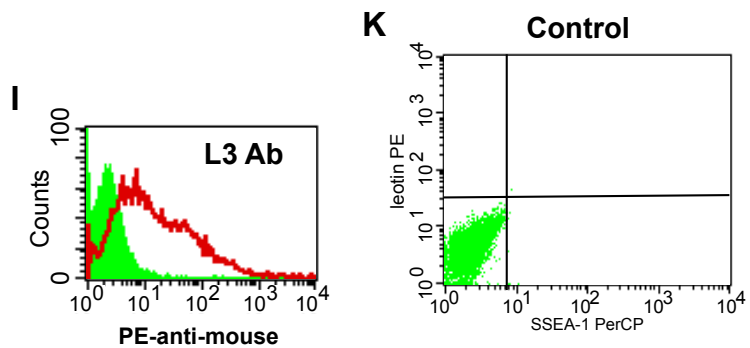

$\mathbf{J}$
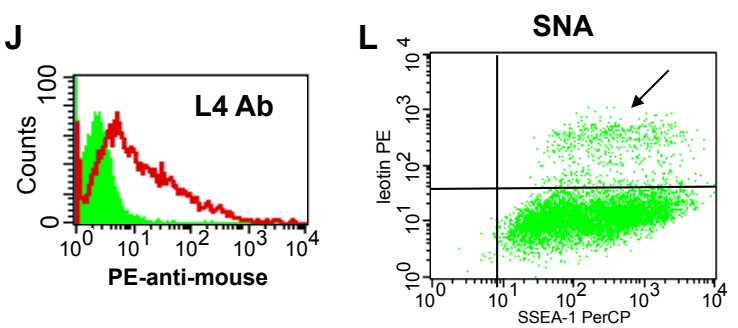

Figure 3: Glycosylation patterns on the cell surface of mouse ES cells. Carbohydrate expression on the cell surface of mouse ES cells was assayed by flow cytometry. The filled green areas show the number of unstained cells and the areas outlined in red represent cells binding to various lectins and carbohydrates antibodies. $A$ : The result for the unstained cells. Figures $3 \mathrm{~K}$ and $3 \mathrm{~L}$ show the double staining results. Figure $3 \mathrm{~K}$ shows plots of unstained mouse ES cells and Figure $3 \mathrm{~L}$ shows subpopulations of cells characterized as SSEA-1(+)/SNA(-) (lower) or SSEA-1(+)/SNA(+) cells (upper, arrow). 


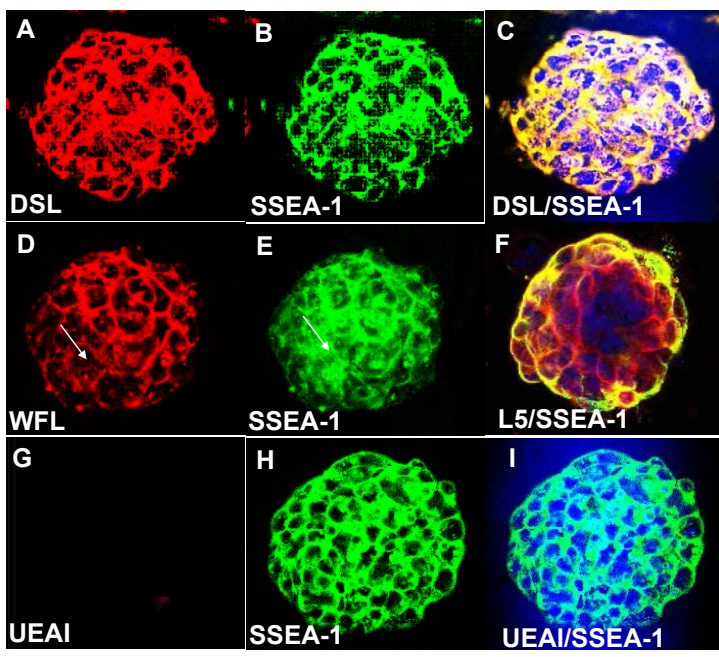

Figure 4: Carbohydrate expression determined by lectins and carbohydrate Abs using immunocytochemistry method. Immunocytochemistry for DSL, WFL, UEAI or L5 (red) in SSEA-1 positive colony (green) indicates different carbohydrate expression patterns.

subsequently assessed for carbohydrate signatures on the cell surface by a panel of carbohydrate antibodies and lectins.

Mouse ES cells appeared to have high levels of mannose and galactose as depicted by the uniform and high expression of $\mathrm{Gal}$ $\beta(1,3)$-GalNAc (PNA and JAC), N-acetyllactosamine (DSL), $\alpha(1,3)$ mannose (GNL) and $\alpha$-D-mannose (PSA). In agreement to our data, Nand has shown that R1 mouse ES cells could be distinguished from mouse embryonic fibroblast stem cells by high lectin bindings of PNA, SNA and Dolichos Biflorus Agglutinin in mouse ES cells compared to fibroblast stem cells [11]. Similarly, high levels of high mannose glycans have been detected on cell surface of human ES cells, in contrast to human somatic cell lines where high mannose glycans are minor components of the cells [22]. Additionally, human ES cells have been shown to highly express poly- $\mathrm{N}$-acetyllactosamine and b-galactosyl residues [13].

Contrary to the aforementioned uniform pattern observed for mannose and galactose, fucosylation, sialylation and $\mathrm{N}$-acetylgalactosamine were only expressed in a partial of the ES cells as depicted by the staining patterns of $\mathrm{N}$-acetylgalactosamine (WFL), $\alpha(1,6)$-L-fucose (AAL) and $\alpha(2,6)-$ GalNAc (SNA). This gave rise to two sub-populations of cells - SSEA(+)/lectin(+) and SSEA(+)/lectin(-). Changes in the pattern of glycosylation are often observed during development and differentiation processes. For example, fucosylation has been implicated in embryonic development, having roles in early embryogenesis, embryo compaction and neurogenesis [23]. A shift from high mannose glycans to high fucosylated and sialylated glycans has also been observed at the cell surface of colorectal adenocarcinoma cells during differentiation [24].

In some mouse ES cell colonies, we also observed a strong staining of SSEA-1 at the periphery of the colony which gradually weakens as it approaches the middle of the colony. Interestingly, this is accompanied by relatively intense staining of L5 antibody which recognizes fucose residues [18]. As cells lose the expression of SSEA-1 and thus, start to differentiate, the carbohydrate presentation on cell surfaces might be altered. L5 is an oligosaccharide which has been found in many glycoproteins and cell recognition molecules, such as the L1 molecules [18]. L1 molecules are carbohydrate carrying molecules which have been shown to be glycan-binding molecules affecting glycosylation processes. For instance, glial CD24 regulates neurite outgrowth by a $(2,3)$-linked sialic acid and Lewis $\mathrm{x}$ trans-interaction with $\mathrm{L} 1$ and TAG and Contactin [25]. L1 has also been shown to influence the expression of glycosyltransferases thereby modulating fucosylation and sialylation, which consequently, regulates ES cell survival and proliferation [26].

Low percentages of Neu5Ac a $(2,3) \mathrm{Gal}$ (MAA, MALII) and $\alpha(1,2)$ L-fucose (UEAI) were observed on the cell surface of the mouse ES cell lines studied. Previously, it has been shown that binding of MAA was increased in mouse embryonic fibroblast stem cells compared to ES cells while UEAI was found to be absent in mouse ES cells [11].

Lectins and carbohydrate antigens have been commonly used to characterize and enrich glycoproteins. The enrichment of glycoproteins by Concanavalin A, wheat germ agglutinin and PNA has allowed the discovery of glycoproteins responsible for the differentiation of glioblastoma stem cells [27]. Furthermore, lectins have also been successfully used to isolate glioma-derived stem cells in neurospheres cultured from a resected cerebellar glioblastoma patient [28]. Polylactosamine-specific DSL has been used for characterization of specific glycans as tumor markers in various cancers [29]. Increased fucosylation as detected by lectins such as AAL and UEA1 was observed in pancreatic cancer stem cells resistant to gemcitabine [30]. Lectins such as MAA, PSA, and UEA1 have been used to elucidate the $\mathrm{N}$-glycan profile of human ES cells during its differentiation stage [31] (Table 1).

Epigenetic factors such as chromatin remodelling, DNA methylation and histone modifications have been widely reported to regulate embryonic stem cells fate and differentiation [5,32]. For example, the augmented expression of histone H3 lysine 9 dimethylation and trimethylation, accompanied by the removal of methylation of lysine 27 of histone $\mathrm{H} 3$ have been observed in the chromatin of pluripotent stem cells during differentiation into specific lineages [32]. Additionally, a comprehensive study done on

\begin{tabular}{|c|c|c|}
\hline Name & $\begin{array}{c}\text { Monosaccharide } \\
\text { specificity }\end{array}$ & Inhibitors \\
\hline L3 Ab & Man & \\
\hline $\mathrm{L} 4 \mathrm{Ab}$ & Man & \\
\hline $\begin{array}{l}\text { PSA (Pisum sativum } \\
\text { agglutinin) }\end{array}$ & Man & $\begin{array}{l}\text { methyl mannoside and } \\
\text { glucoside mixture }\end{array}$ \\
\hline $\begin{array}{l}\text { GNL (Galanthus nivalis } \\
\text { lectin) }\end{array}$ & Man & alpha-methyl mannoside \\
\hline L5 Ab & Fuc & \\
\hline $\begin{array}{l}\text { LTL (Lotus tetragonolobus } \\
\text { lectin) }\end{array}$ & Fuc & L-fucose \\
\hline $\begin{array}{l}\text { UEAI (Ulex europaeus } \\
\text { agglutinin I) }\end{array}$ & Fuc & L-fucose \\
\hline AAL (Aleuria aurantia lectin) & Fuc & L-fucose \\
\hline PNA (Peanut agglutinin) & Gal & galactose \\
\hline Jacalin & Gal & galactose or melibiose \\
\hline $\begin{array}{c}\text { MAA (Maackia amurensis } \\
\text { lectin II) }\end{array}$ & Sialic acid & human glycophorin \\
\hline SNA (Sambucus nigra) & Sialic acid & lactose \\
\hline $\begin{array}{l}\text { DSL (Datura stramonium } \\
\text { lectin) }\end{array}$ & lactosamine & chitin hydrolysate \\
\hline $\begin{array}{l}\text { WFL (Wisteria floribunda } \\
\text { lectin) }\end{array}$ & GalNAc & $\begin{array}{c}\mathrm{N} \text {-acetylgalactosamine or } \\
\text { acetic acid }\end{array}$ \\
\hline
\end{tabular}

Table 1: Data regarding the lectins and antibodies used in this study. Lectins and carbohydrate antibodies used in this study. The chosen carbohydrate Abs and lectins, their commonly abbreviated names, the specificity of these Abs and lectins to their respective monosaccharides and the competitive sugar that was used to verify its respective specificity. 
Citation: He Z, An Y, Shi G, Lin Y, Hu J, et al. (2016) Characterization of Carbohydrate Surface Markers on Mouse Embryonic Stem Cells. J Stem Cell Res Ther 6: 353. doi: 10.4172/2157-7633.1000353

the dynamics of transcription and epigenetic factors during human embryonic stem cell lineage specification suggested that the transition of high DNA methylation status to enrichment of histone markers such as $\mathrm{H} 3 \mathrm{~K} 4 \mathrm{me} 1$ or $\mathrm{H} 3 \mathrm{~K} 27 \mathrm{me} 3$ is a common event during this process [33]. DNA methylation status has also been shown to regulate many surface marker associated genes, one of which is the Placenta Expressed Transcript 1 (PLET1) [34]. The maintenance of DNA methylation is highly regulated by DNA methyltransferases, such as Dnmt3a and Dnmt3b, as well as some histone methyltransferases such as histone H3 lysine 9 methylases G9a and GLP and these enzymes have been shown to be essential in mammalian embryonic development [3537]. As such, the expression of certain surface markers might strongly reflect the activity of these enzymes. It has been demonstrated that the cell surface glycoprotein, gp130-mediated astrocyte differentiation is highly influenced by the methylation status of the STAT3 binding site in neural stem cells, which is postulated to be regulated by DNA methyltransferases $[38,39]$. The expression of stem cell markers such as CD44, CD34 and EpCAM in colon cancer has also been proven to be dependent on its methylation state $[40,41]$. Therefore, to better understand lineage commitment and isolate a specific sub-group of ES cells, it would be interesting to investigate the link between the expression of surface marker and the profiling of DNA methylation. This could be done in conjunction with lectin profiling which is reflective of carbohydrate markers present on stem cell surface.

Taken together, using a panel of 14 carbohydrate antigens and lectins, the study has shown that mouse ES cells possess a wide range of carbohydrate antigens that can be used as surface markers which are potentially useful for further studies on mouse ES.7.

\section{Acknowledgements}

This work was supported by grants to Y.L. Li from National Natural Science Foundation of China (31070728) and J.L. Hu from Shenzhen Governmental Basic Research Grant (JCYJ20140416122812008).

\section{References}

1. Evans MJ, Kaufman MH (1981) Establishment in culture of pluripotential cells from mouse embryos. Nature 292: 154-156. [PubMed]

2. Martin GR (1981) Isolation of a pluripotent cell line from early mouse embryos cultured in medium conditioned by teratocarcinoma stem cells. Proc Natl Acad Sci U S A 78: 7634-7638. [PubMed]

3. Mak TW (2007) Gene targeting in embryonic stem cells scores a knockout in Stockholm. Cell 131: 1027-1031. [PubMed]

4. Loh YH, Wu Q, Chew JL, Vega VB, Zhang W, et al. (2006) The Oct4 and Nanog transcription network regulates pluripotency in mouse embryonic stem cells. Nat Genet 38: 431-440

5. Calvanese V, Fraga MF (2012) Epigenetics of embryonic stem cells. Adv Exp Med Biol 741: 231-253. [PubMed]

6. Henderson JK, Draper JS, Baillie HS, Fishel S, Thomson JA, et al. (2002) Preimplantation human embryos and embryonic stem cells show comparable expression of stage-specific embryonic antigens. Stem Cells 20: 329-337. [PubMed]

7. Solter D, Knowles BB (1978) Monoclonal antibody defining a stage-specific mouse embryonic antigen (SSEA-1). Proc Natl Acad Sci U S A 75: 5565-5569. [PubMed]

8. Zhao W, Ji X, Zhang F, Li L, Ma L (2012) Embryonic stem cell markers. Molecules 17: 6196-6236 [PubMed]

9. Wang YC, Nakagawa M, Garitaonandia I, Slavin I, Altun, G, et al. (2011) Specific lectin biomarkers for isolation of human pluripotent stem cells identified through array-based glycomic analysis. Cell Res 21: 1551-1563. [PubMed]

10. Venable A, Mitalipova M, Lyons I, Jones K, Shin S, et al. (2005) Lectin binding profiles of SSEA-4 enriched, pluripotent human embryonic stem cell surfaces. BMC Dev Biol 5: 15. [PubMed]
11. Nand A, Singh V, Wang P, Na J, Zhu J (2014) Glycoprotein profiling of stem cells using lectin microarray based on surface plasmon resonance imaging. Anal Biochem 465: 114-120. [PubMed]

12. Toyoda M, Yamazaki-Inoue M, Itakura Y, Kuno A, Ogawa T, et al. (2011) Lectin microarray analysis of pluripotent and multipotent stem cells. Genes Cells 16 1-11. [PubMed]

13. Wearne KA, Winter HC, O'Shea K, Goldstein IJ (2006) Use of lectins for probing differentiated human embryonic stem cells for carbohydrates. Glycobiology 16 : 981-990. [PubMed]

14. Khosravi-Farsani S, Amidi F, Roudkenar MH, Sobhani A (2015) Isolation and enrichment of mouse female germ line stem cells. Cell J 16: 406-415. [PubMed]

15. Toumadje A, Kusumoto K, Parton A, Mericko P, Dowell L, et al. (2003) Pluripotent differentiation in vitro of murine ES-D3 embryonic stem cells. In Vitro Cell Dev Biol Anim 39: 449-453. [PubMed]

16. Kucherer A, Faissner A, Schachner M (1987) The novel carbohydrate epitope L3 is shared by some neural cell adhesion molecules. J Cell Biol 104: 15971602. [PubMed]

17. Fahrig T, Schmitz B, Weber D, Kucherer-Ehret A, Faissner A, et al. (1990) Two monoclonal antibodies recognizing carbohydrate epitopes on neural adhesion molecules interfere with cell interactions. Eur J Neurosci 2: 153-161. [PubMed]

18. Streit A, Faissner A, Gehrig B, Schachner M (1990) Isolation and biochemical characterization of a neural proteoglycan expressing the $L 5$ carbohydrate epitope. J Neurochem 55: 1494-1506. [pubMed]

19. Streit A, Yuen CT, Loveless RW, Lawson AM, Finne J, et al. (1996) The Lex carbohydrate sequence is recognized by antibody to $L 5$, a functional antigen in early neural development. J Neurochem 66: 834-844. [PubMed]

20. Oka M, Tagoku K, Russell TL, Nakano Y, Hamazaki T, et al. (2002) CD9 is associated with leukemia inhibitory factor-mediated maintenance of embryonic stem cells. Mol Biol Cell 13: 1274-1281 [PubMed]

21. Wright AJ, Andrews PW (2009) Surface marker antigens in the characterization of human embryonic stem cells. Stem Cell Res 3: 3-11. [PubMed]

22. An HJ, Gip P, Kim J, Wu S, Park KW, et al. (2012) Extensive determination of glycan heterogeneity reveals an unusual abundance of high mannose glycans in enriched plasma membranes of human embryonic stem cells. Mol Cell Proteomics 11: M111 010660. [PubMed]

23. Becker DJ, Lowe JB (2003) Fucose: biosynthesis and biological function in mammals. Glycobiology 13: 41R-53R. [PubMed]

24. Park D, Brune KA, Mitra A, Marusina Al, Maverakis E, et al. (2015) Characteristic Changes in Cell Surface Glycosylation Accompany Intestinal Epithelial Cell (IEC) Differentiation: High Mannose Structures Dominate the Cell Surface Glycome of Undifferentiated Enterocytes. Mol Cell Proteomics 14: 2910-2921. [PubMed]

25. Lieberoth A, Splittstoesser F, Katagihallimath N, Jakovcevski I, Loers G, et al. (2009) Lewis $(x)$ and alpha2,3-sialyl glycans and their receptors TAG-1, Contactin, and L1 mediate CD24-dependent neurite outgrowth. J Neurosci 29: 6677-6690. [PubMed]

26. Li YL, Wu GZ, Zeng L, Dawe GS, Sun L, et al. (2009) Cell surface sialylation and fucosylation are regulated by the cell recognition molecule L1 via PLCgamma and cooperate to modulate embryonic stem cell survival and proliferation. FEBS Lett 583: 703-710. [PubMed]

27. He J, Liu Y, Zhu TS, Xie X, Costello MA, et al. (2011) Glycoproteomic analysis of glioblastoma stem cell differentiation. J Proteome Res 10: 330-338. [PubMed]

28. Tucker-Burden C, Chappa P, Krishnamoorthy M, Gerwe BA, Scharer CD, et al (2012) Lectins identify glycan biomarkers on glioblastoma-derived cancer stem cells. Stem Cells Dev 21: 2374-2386. [PubMed]

29. Mitsui Y, Yamada K, Hara S, Kinoshita M, Hayakawa T, et al. (2012) Comparative studies on glycoproteins expressing polylactosamine-type $\mathrm{N}$-glycans in cancer cells. J Pharm Biomed Anal 70: 718-726. [PubMed]

30. Terao N, Takamatsu S, Minehira T, Sobajima T, Nakayama K, et al. (2015) Fucosylation is a common glycosylation type in pancreatic cancer stem cell-like phenotypes. World J Gastroenterol 21: 3876-3887. [Pubmed]

31. Satomaa T, Heiskanen A, Mikkola M, Olsson C, Blomqvist M, et al. (2009) The $\mathrm{N}$-glycome of human embryonic stem cells. BMC Cell Biol 10: 42. [PubMed] 
Citation: He Z, An Y, Shi G, Lin Y, Hu J, et al. (2016) Characterization of Carbohydrate Surface Markers on Mouse Embryonic Stem Cells. J Stem Cell Res Ther 6: 353. doi: 10.4172/2157-7633.1000353

32. Lunyak VV, Rosenfeld MG (2008) Epigenetic regulation of stem cell fate. Hum Mol Genet 17: R28-36. [PubMed]

33. Gifford CA, Ziller MJ, Gu H, Trapnell C, Donaghey J, et al. (2013) Transcriptional and epigenetic dynamics during specification of human embryonic stem cells Cell. 153: 1149-1163. [PubMed]

34. Murray A, Sienerth AR, Hemberger M (2016) Plet1 is an epigenetically regulated cell surface protein that provides essential cues to direct trophoblast stem cell differentiation. Sci Rep 6: 25112

35. Li E, Bestor TH, Jaenisch R (1992) Targeted mutation of the DNA methyltransferase gene results in embryonic lethality. Cell 69: 915-926. [PubMed]

36. Okano M, Bell DW, Haber DA, Li E (1999) DNA methyltransferases Dnmt3a and Dnmt3b are essential for de novo methylation and mammalian development. Cell 99: 247-257. [PubMed]
37. Zhang T, Termanis A, Ozkan B, Bao XX, Culley J, et al (2016) G9a/GLP Complex Maintains Imprinted DNA Methylation in Embryonic Stem Cells. Cell Rep 15: 77-85. [Pubmed]

38. Takizawa T, Nakashima K, Namihira M, Ochiai W, Uemura A, et al. (2001) DNA methylation is a critical cell-intrinsic determinant of astrocyte differentiation in the fetal brain. Dev Cell 1: 749-758. [PubMed]

39. Yanagisawa M, Yu RK (2007) The expression and functions of glycoconjugates in neural stem cells. Glycobiology 17: 57R-74R. [PubMed]

40. Yi JM (2012) DNA methylation of stem cell surface markers in colon cancers. Genes \& Genomics 34: 299-304

41. Cui L, Johkura K, Yue F, Ogiwara N, Okouchi Y, et al. (2004) Spatial distribution and initial changes of SSEA-1 and other cell adhesion-related molecules on mouse embryonic stem cells before and during differentiation. J Histochem Cytochem 52: 1447-1457 [PubMed] 